\title{
FastText ve Kelime Çantası Kelime Temsil Yöntemlerinin Turistik Mekanlar İçin Yapılan Türkçe İncelemeler Kullanılarak Karşıllaştırılması
}

\author{
Muhammed Çağrı Aksu ${ }^{1 *}$, Ersin Karaman ${ }^{2}$ \\ ${ }^{1 *}$ Artvin Çoruh Üniversitesi, Rektörlük, Enformatik Bölümü, Artvin, Türkiye, (ORCID: 0000-0002-8577-4413), m.cagri.aksu@gmail.com \\ ${ }^{2}$ Atatürk Üniversitesi, İktisadi ve İdari Bilimler Fakültesi, İşletme Bölümü, Erzurum, Türkiye (ORCID: 0000-0002-6075-2779), karamanersin@gmail.com
}

(İlk Geliş Tarihi 3 Ağustos 2020 ve Kabul Tarihi 14 Ekim 2020)

(DOI: $10.31590 /$ ejosat.776629)

\begin{abstract}
ATIF/REFERENCE: Aksu, M. Ç. \& Karaman, E. (2020). FastText ve kelime çantası kelime temsil yöntemlerinin turistik mekanlar
\end{abstract} için yapılan Türkçe incelemeler kullanılarak karşılaştırılması. Avrupa Bilim ve Teknoloji Dergisi, (20), 311-320.

Öz

Günümüzde sosyal medya platformlarının sayısının ve kullanımının artmasıyla birlikte artık insanlar satın aldıkları bir ürünle veya gittikleri bir yer ile ilgili deneyimlerini sosyal medya platformlarında daha sıklıkla paylaşmaktadırlar. Sosyal medya platformlarındaki verilerin hacmi düşünüldüğünde, sosyal medya platformlarında paylaşılan incelemeler ve deneyimler içerisinde kurumlar veya şirketler için anlamlı birtakım bilgilerin olduğu düşünülmektedir. Hal böyle olunca sosyal medyada paylaşılan incelemeler ve deneyimler içerisinden anlamlı bilgi çıkarma yöntemlerini daha iyi hale getirmek ve hangi yöntemin daha iyi olduğunu bilmek önem arz etmektedir. Bu çalışmada turistik mekanlar için yapılan Türkçe incelemeler kullanılarak, yukarıda bahsedilen yöntemlerden biri olan duygu analizi yöntemindeki kelime temsil yöntemlerinden kelime çantası ve fastText kelime temsil yöntemlerinin sınıflandırma başarıları karşılaştırılmıştır. Ayrıca karşılaştırma işlemi gerçekleştirilirken duygu analizi işleminin ön hazırlık aşaması olan kelimeleri köklerine ayırma ve kelimeleri olumsuzlaştırma işlemlerinin sınıflandırma başarısına katkılarının olup olmadığı ölçülmüştür. Çalışmada hem iki sınıflı (pozitif, negatif) duygu analizi hem de üç sınıflı (pozitif, negatif, nötr) duygu analizi gerçekleştirilmiştir. Bahsedilen karşılaştırma işlemlerini gerçekleştirebilmek için altı adet veri seti oluşturulmuştur. Veri setleri önce metin madenciliğinde sıklıkla kullanılan Naive Bayes (NB), Multinom Naive Bayes (MNB), k-Nearest Neighbor (k-NN) ve Support Vector Machines (SVM) algoritmaları kullanılarak ve kelime çantası kelime temsil yöntemi esas alınarak WEKA programıyla sınıflandırılmıştır. Tüm veri setlerinin kelime çantası kelime temsil yöntemine göre test sonuçları elde edildikten sonra fastText kelime temsil yöntemine dair testler python programlama dilinin fastText kütüphanesi kullanılarak gerçekleştirilmiştir. Sınıflandırma işlemleri 10 tekrarlı çapraz doğrulama yöntemiyle yapılarak sınıflandırma işlemlerinin f-skor değerleri elde edilmiştir. Nihayetinde iki sınıflı duygu analizinde kelime çantası kelime temsil yönteminin fastText kelime temsil yönteminden daha başarılı sınıflandırma gerçekleştirdiği, üç sınıflı duygu analizinde ise tam tersi bir şekilde fastText kelime temsil yönteminin kelime çantası kelime temsil yönteminden daha başarılı sınıflandırma işlemi gerçekleştirdiği tespit edilmiştir. Duygu analizi ön hazırlık işlemlerinden kelimeleri köklerine ayırma ve olumsuzlaştırma işlemlerinin fastText kelime temsil yöntemiyle gerçekleştirilen sınıflandırma işlemlerinde olumlu ya da olumsuz bir katkı sağlamadığı görülmüştür. Ancak kelime çantası kelime temsil yöntemi kullanılarak gerçekleştirilen duygu analizi işlemlerinde az da olsa bir katkısının olduğu tespit edilmiştir. İki sınıflı duygu analizinde en başarılı sınıflandırma sonucuna kelime çantası kelime temsil yöntemi kullanılarak $0.91 \mathrm{f}$-skoru değeriyle SVM algoritmasıyla oluşturulan makine öğrenmesi modeliyle ulaşılmıştır. Üç sınıflı duygu analizinde ise en başarılı sınıflandırma sonucuna $0.78 \mathrm{f}$-skoru değeriyle fastText kelime temsil yöntemi kullanılarak oluşturulan makine öğrenmesi modeliyle ulaşılmıştır.

Anahtar Kelimeler: Metin madenciliği, Duygu analizi, Kelime temsil yöntemleri, Kelime çantası, FastText, Makine öğrenmesi.

\section{Comparison of fast Text and Bag of Words Word Representation Methods by Using Turkish Reviews Conducted for Touristic Places}

\begin{abstract}
Nowadays, with the increasing number and use of social media platforms, people now share their experiences about a product they have bought or a place they have been to on social media platforms more frequently. Considering the volume of data on social media
\end{abstract}

* Sorumlu Yazar: m.cagri.aksu@gmail.com 
platforms, it is considered that there is some meaningful information for institutions or companies in the reviews and experiences shared on social media platforms. As such, it is important to improve the methods of extracting meaningful information from the reviews and experiences shared on social media and to know which method is better. In this study, the classification successes of the bag of words and the fastText word representation methods, which are among the word representation methods in sentiment analysis methods mentioned above, were compared by using Turkish reviews performed for touristic places. Besides, while performing the comparison process, it was measured whether the process of separating the words into their roots and negation of the words, which is the preliminary stage of the sentiment analysis process, contributed to the classification success. In the study, both two-class (positive, negative) sentiment analysis and three-class (positive, negative, neutral) sentiment analysis were performed. Six data sets were created to carry out the mentioned comparison operations. The data sets were first classified using the Naive Bayes (NB), Multinomial Naive Bayes (MNB), k-Nearest Neighbor (k-NN) and Support Vector Machines (SVM) algorithms, which are frequently used in text mining, and based on bag of words word representation method, they were classified with WEKA program. After the test results of all data sets were obtained according to the bag of words word representation method, the tests of the fastText word representation method were carried out using the fastText library of the Python programming language. Classification procedures were carried out with 10 -fold crossvalidation methods, and f-score values of the classification processes were obtained. Finally, it was determined that bag of words word representation method performed a more successful classification than the fastText word representation method in two-class emotion analysis, while the fastText word representation method performed a more successful classification process than bag of words word representation method in three-class emotional analysis. It was observed that the process of separating the words into their roots and negating the words, which are the preliminary processes of sentiment analysis, did not contribute positively or negatively to the classification processes performed with the fastText word representation method. However, it was determined that it had a minor contribution to sentiment analysis processes performed by using bag of words word representation method. In the two-class sentiment analysis, the most successful classification result was achieved by using the machine learning model created with the SVM algorithm with the value of $0.91 \mathrm{f}$-score employing bag of words word representation method. In the three-class sentiment analysis, the most successful classification result was achieved with the machine learning model created using the fastText word representation method with the value of $0.78 \mathrm{f}$-score.

Keywords: Text mining, Sentiment analysis, Word representation methods, Bag of words, Fast Text, Machine learning.

\section{Giriş}

Günümüzde sosyal medyada oluşan veriler, değerli bilgiler elde etmek için önemli bir kaynak haline gelmiştir. Gelişen teknolojiyle birlikte bir metin madenciliği tekniği olan duygu analizi kullanılarak sosyal medya kaynaklarından birtakım anlamlı bilgiler çıkarmak mümkün hale gelmiştir. Duygu analizi vasıtasıyla insanların hizmetler, bireyler, konular, ürünler gibi varlıklara yönelik duyguları, tutumları ve değerlendirmeleri analiz edilebilmektedir (Liu, 2012). Özellikle incelemeler, yorumlar gibi kullanıcılar tarafından üretilen içerikler birçok şirket tarafindan pazarlama faaliyetlerinde kullanılmaktadır (Ait Hammou vd., 2020). Bu içerikler sadece pazarlama faaliyetlerinde kullanılmamaktadır, aynı zamanda karar verme ve tahmin alanlarında da kullanılmaktadır (Kızılkaya, 2018; Yüksel \& Gülşah, 2018). Duygu analizi çalışmaları birçok alanda yapıldığı gibi turizm alanında da yapılmakta ve genellikle müşteri ilişkileri yönetiminde kullanılmakta ve müşterilerin ürettikleri içeriklerle müşterilerin duyguları, tutumları ve değerlendirmeleri analiz edilmektedir (Neri vd., 2012). Turizm alanında yapılan duygu analizi çalışmalarının birçoğu oteller ve restoranlar için yapılan incelemeler kullanılarak yapılmakta ve bu çalışmalar genellikle bir şirketi muhatap almaktadır. Özellikle yerel yönetimleri muhatap alan ve bir bölgedeki doğal ve kültürel varlıklar için yapılmış duygu analizi çalışması yok denecek kadar azdır (Aydoğan \& Akcayol, 2016; Can \& Alataş, 2017; Karaoğlan vd., 2019; Özyurt \& Akçayol, 2018). Ayrıca alan yazında İngilizce içerikler kullanılarak yapılan birçok duygu analizi çalışması olmasına rağmen Türkçe içerikler kullanılarak yapılmış duygu analizi çalışmalarının oldukça kısıtlı olduğu görülmektedir (Aydoğan \& Akcayol, 2016; Can \& Alataş, 2017; Çoban vd., 2015; Özyurt \& Akçayol, 2018). Türkçe içerikler kullanılarak gerçekleştirilen duygu analizi çalışmaları genellikle çeşitli makine öğrenmesi tekniklerinin karşılaştırılması üzerinedir (Kaya vd., 2012; Türkmenoglu \& Tantug, 2014; Yüksel \& Gülşah, 2018). Kaynar vd. (2016) film yorumlarını veri olarak kullanarak naive bayes, merkez tabanlı sınıflayıcı, çok katmanlı yapay sinir ağları ve destek vektör makineleri gibi çeşitli makine öğrenmesi yöntemleriyle duygu analizi gerçekleştirerek yapay sinir ağlarının ve destek vektör makinalarının diğer yöntemlere göre daha iyi sonuç verdiğini saptamışlardır. Çoban vd. (2015) twitter verilerini kullanarak çeşitli makine öğrenmesi algoritmalarının sınıflandırma başarısını ölçtükleri duygu analizi çalışmasında, $\% 66,06$ doğru sınıflandırma yüzdesiyle multinominal naive bayes algoritmasıyla en başarılı sınıflandırma sonucuna ulaşmışlardır.

Duygu analizi çalışmalarında duygu sınıflandırması yaprlabilmesi için metinlerin bir şekilde bilgisayarın anlayabileceği şekle yani sayısal hale dönüştürülmesi gerekmektedir. Metinler vektör uzay modeli, kelime çantası yöntemi (BOW), Word2Vec gibi yöntemlerle sayısal hale dönüştürülmektedir (Albayrak, 2018). Duygu analiziyle ilgili alan yazındaki çalışmaların bir kısmı da bu yöntemlerin karşılaştırılması üzerinedir. Alessa vd. (2018) Word2Vec altyapısını kullanan fastText algoritmasıly grip konusunu içeren tweetleri sinıflandırarak, fastText'in RandomForest tekniğinden hız ve doğruluk anlamında daha iyi sonuçlar verdiğini saptamışlardır. Velioğlu vd. (2018) Türkçe twitter verilerini kelime çantası yöntemiyle sayısal hale getirdikten sonra lineer regresyon algoritmasıyla bir model oluşturmuşlardır. Daha sonra aynı veriler ile Word2 Vec kelime temsil yöntemine dayalı fastText algoritmasıyla başka bir model oluşturmuşlardır. Son olarak bu iki modeli karşılaştırdıklarında iki model arasında anlamlı bir farkın olmadığını tespit etmişlerdir. Bir başka çalışmada da Bilgin ve Şentürk (2017) Doc2Vec metin temsil yöntemini kullanarak duygu analizi çalışması yapmışladır. Bu çalışmada DBOW (Disturbuted bag of words) yönteminin DM'den (Disturbuted Memory) daha başarılı olduğu tespit edilmiştir.

İlgili çalışmalardan anlaşılacağı üzere Türkçe duygu analizi çalışmaları genellikle belirli yöntemlerin birbirleriyle karşılaştırılması üzerinedir. Bu çalışmada turizm yöneticilerini muhatap alan ve bir bölgedeki doğal ve kültürel varlıklar için duygu analizi yapmaya imkân sağlayacak bir makine öğrenmesi modeli geliştirmek hedeflemektedir. Bu hedefi gerçekleştirirken de duygu analizinde kullanılan kelime temsil yöntemlerinden olan 
kelime çantası ve fastText kelime temsil yöntemlerinden hangisinin daha başarılı sınıflandırma yaptığını tespit etmek amaçlanmaktadır. Karşılaştırma işlemi gerçekleştirilirken duygu analizi işleminin ön hazırlık aşamalarından olan kelimeleri köklerine ayırma ve kelimeleri olumsuzlaştırma işlemlerinin sınıflandırma başarısına katkılarının olup olmadığı ölçülmeye çalışılmıştır. Çalışmamız bu yönüyle önem arz etmektedir. Ayrıca alan yazındanki Türkçe içeriklerle gerçekleştirilen duygu analizi çalışmalarının kısıtlı olması ve çalışmamızın Türkçe içeriklerle gerçekleştirilen bir duygu analizi çalışması olması münasebetiyle çalışmanın alan yazına katkı sağlayacağı beklenmektedir.

\section{Materyal ve Metot}

Çalışmamız bir Türkçe duygu analizi çalışmasıdır. Duygu analizi, insanların ürünler, etkinlikler, konular, bireyler, organizasyonlar gibi varlıklara yönelik incelemelerini, tutumlarını ve duygularını analiz eden bir çalışma alanıdır (Liu, 2012). Duygu analizi işleminde genellikle bir duygu, pozitif ve negatif olarak ikili sınıflandırıldığı gibi pozitif, negatif ve nötr olarak üçlü sınıflandırma da yapılmaktadır (Şeker, 2016). Bu çalışmada hem ikili hem de üçlü sınıflandırma gerçekleştirilmiştir.

Duygu analizi, makine öğrenmesi yöntemi ve sözlük tabanlı yöntem olmak üzere iki şekilde yapılabilmektedir (Can \& Alataş, 2017). Makine öğrenmesi yönteminde etiketlenmiş yani bir şekilde sınıfları tayin edilmiş verilerle bir model oluşturulmaktadır. Daha sonra sınıfı bilinmeyen verilerin sınıfları bu model kullanılarak tespit edilmektedir (Pang vd., 2002). Sözlük tabanlı sınıflandırmada ise görüş kutbu belli olan kelimelerden oluşan bir sözlük bulunmaktadır. Bu sözlükte her bir kelimenin görüş kutbu (pozitiflik, negatiflik, nötrlük) değerleri bulunmaktadır. Sinıflandırılacak metinlerdeki her bir kelime bu sözlükte aranarak metnin duygu polaritesi hesaplanmaktadır (Baccianella vd., 2010; Esuli \& Sebastiani, 2006; Ku vd., 2006). $\mathrm{Bu}$ çalışmada, alan yazında daha üstün bir yöntem olduğu belirtildiği için makine öğrenmesi yöntemi kullanılmıştır (Özyurt \& Akçayol, 2018). Makine öğrenimi yöntemiyle gerçekleştirilen duygu analizi aslında bir sınıflandırma işlemidir ve metnin duygu sınıfını tahmin etmekten ibarettir. Makine öğrenimiyle yapılacak

Tablo 1. Turistik Mekanlar için Yapılan Türkçe Inceleme Örnekleri oluşmaktadır. açıklanmıştır.

duygu analizi için duygu sınıflarının makineye yani bilgisayara tanıtılması gerekmektedir. Yani makineye hangi tür metinlerde hangi duygu polaritesi sonucunu üreteceğinin öğretilmesi gerekmektedir. Bunun için veri setlerine, veri setlerini oluşturmak içinse veriye ihtiyaç duyulmaktadır. Bu çalışmada veri setlerini oluşturabilmek için Türkiye'nin üç iline (Trabzon, Rize, Artvin) ait turistik mekanlar için yapılan incelemeler, çeşitli sosyal medya platformlarından veri kazıma yöntemiyle alınmıştır. Sosyal medya platformu olarak, alan yazındaki çalışmalarda sıklıkla kullanılan ve turistlerin gittikleri yerlerle ilgili incelemeler ya da yorumlar yapmasına imkân sağlayan siteler olan Google Haritalar, Foursquare ve Tripadvisor siteleri kullanılmıştır. Verilerin toplandığı tarih olan 10.03.2020 tarihinde 203 turistik mekân için toplamda 49031 adet inceleme belirtilen sitelerden veri kazıma yöntemiyle alınarak bu çalışmada gerçekleştirilen duygu analizinde kullanılacak veri setlerini oluşturmak için kullanılmıştır. Tablo 1'de görüldüğü gibi belirtilen sitelerden alınan veriler, turistik mekân için turistler tarafından yapılan inceleme, turistik mekân için turistlerin vermiş olduğu puan ve turistlerin yapmış olduğu incelemenin tarihi alanlarından

Buraya kadarki kısımdan anlaşılacağı üzere bu çalışmada turistik mekanlar için yapılan Türkçe incelemeler kullanılarak makine öğrenmesi yöntemleriyle bir duygu analizi çalışması yapılmaktadır. Makine öğrenmesi yöntemiyle yapılan duygu analizi çalışmalarında, duygu sınıfı tespit edilecek metinlerin, bir şekilde bilgisayarın anlayabileceği şekle yani sayısal hale dönüştürülmesi gerekmektedir. Metinler, vektör uzay modeli, kelime çantası modeli (BOW), Word2Vec gibi yöntemlerle sayısal hale dönüştürülmektedir (Albayrak, 2018). Bu yöntemler, kelime temsil yöntemleri olarak adlandırılmaktadır. $\mathrm{Bu}$ çalışmada belirtilen kelime temsil yöntemlerinden kelime çantası ve Word2Vec yönteminin bir uzantısı olan FastText yöntemi karşılaştırılmaktadır. Ayrıca duygu analizi işleminin ön hazırlık adımlarından olan kelimeleri olumsuzlaştırma ve kelimeleri köklerine ayırma işlemlerinin sınıflandırma başarısına olan etkisi ölçülmeye çalışılmıştır. Bu bölümün alt başlıklarında çalışmada ismi geçen terimler daha iyi anlaşılabilmesi için kısaca

\begin{tabular}{l|cc}
\hline İnceleme & Puan & Tarih \\
\hline Muhteşem manzara. Gidip görülmesi gereken bir yer. & 5 & 10.03 .2020 \\
\hline Her geçen gün doğası biraz daha bozuluyor & 1 & 10.05 .2019 \\
\hline Tarihi konumu var. Hediyelik eşyaların satıldı̆̆ı yerler var. & 3 & 10.01 .2020 \\
\hline
\end{tabular}

\subsection{Duygu Analizi}

Duygu analizi, insanların ürünler, etkinlikler, konular, bireyler, organizasyonlar gibi varlıklara yönelik incelemelerini, tutumlarını ve duygularını analiz eden bir çalışma alanıdır (Liu, 2012). Duygu analizi işleminde genellikle bir duygu, pozitif ve negatif olarak ikili sınıflandırıldığı gibi pozitif, negatif ve nötr olarak üçlü sınıflandırma da yapılmaktadır (Şeker, 2016). Duygu analizi çalışmalarında sınıflandırma başarısını artırmak ve öznitelik sayısını düşürebilmek adına terimlerine ayırma, terim normalleştirme, kök bulma, durak kelimeleri çıkarma, terim ağırlıklandırma, olumsuzlaştırma gibi bir takım ön işlemler analiz yapılacak verilere uygulanmaktadır (Aydoğan \& Akcayol, 2016; Çoban, 2016; Çoban vd., 2015; Meral \& Diri, 2014; Saad, 2010; Türkmenoğlu, 2015). Aşağıda bu işlemler kısaca açıklanmıştır.

\subsubsection{Terimlerine Ayırma}

Terimlerine ayırma işlemi kelimelere göre veya harflere göre yapılabilmektedir. N-gram olarak adlandırılan yöntem ile sınıflandırılacak metin, şeçilen $\mathrm{n}$ değeri kadar terime ayrılmaktadır. Örneğin kelime tabanlı terimlerine ayırma işleminde $n$ değeri 1 olarak alındığında, her bir kelime bir terim olarak değerlendirilmektedir. Harf tabanlı terimlerine ayırma işleminde ise n değeri 3 olarak ele alındığında, metin her terimde 
üçer harf olacak şekilde terimlerine ayrılmakta ve her üç harflik grup bir terim olarak değerlendirilmektedir.

\subsubsection{Terim Normalleştirme}

Sinıflandırması yapılacak metinlerde bir takım yazım yanlışları bulunabilmektedir. Özellikle sosyal medyada yazılan Türkçe incelemelerde veya yorumlarda Türkçe karakterlerin yerine İngilizce karakterlerin kullanıldı̆̆ı yaygın bir şekilde görülmektedir. $\mathrm{Bu}$ yazım hatalarının giderilmesi işlemine terim normalleştirme denilmektedir. Türkçe duygu analizi çalışmalarında bu işlem genellikle Zemberek-NLP ${ }^{2}$ doğal dil işleme aracı kullanılarak gerçekleştirilmektedir.

\subsubsection{Kök Bulma}

Duygu analizi çalışmalarında özellikle metin içerisindeki her bir kelime bir terim olarak ele alındığında öznitelik sayısı metin içerisinde geçen tekil kelime sayısına denk gelmektedir. Bu durum öznitelik miktarının fazla olmasına neden olmaktadır. Bunun önüne geçebilmek için yani öznitelik sayısını düşürebilmek için terimlerin kökleri saptanmaktadır. Böylece aynı kökten türemiş kelimeler tek bir öznitelik olarak değerlendirilmekte ve neticesinde öznitelik sayısı azalmaktadır. Kök bulma işlemi bir doğal dil işleme çalışmasıdır ve Türkçe metinler için genellikle Zemberek-NLP kullanılarak gerçekleştirilmektedir (Akın \& Akın, 2007).

\subsubsection{Durak Kelimeleri Çıkarma}

Durak kelimeler bağlaçlar gibi cümlenin duygusuna herhangi bir etkisi olmayan kelimelerdir (Sevindi, 2013). Duygu analizi çalışmalarında durak kelimeler genellikle öznitelik sayısını düşürebilmek için duygu analizi yapılacak olan metinden çıkarılmaktadır (Çoban, 2016; Kaynar vd., 2016; Meral \& Diri, 2014). Durak kelime çıkarma işlemi, duygu analizi çalışmasındaki metinlerde geçen her bir kelimenin önceden hazırlanmış durak kelime listesinde aranmasıyla ve daha sonra bulunan kelimelerin duygu analizi yapılacak metinlerden çıkartılmasıyla gerçekleştirilmektedir.

\subsubsection{Olumsuzlaştırma}

Türkçe'nin sondan eklemeli bir dil olması münasebetiyle kelimelerde olumsuzlaştırma genellikle sonradan eklenen eklerle yapılmaktadır. Örneğin Zemberek-NLP, "gelmiyor" sözcüğünün kökünü "gel" olarak tespit etmektedir. Böylece olumsuz olan bir kelime olumlu hale gelmiş olmaktadır. Bu durumunun üstesinden gelebilmek için duygu analizi çalışmalarında olumsuzlaştırma yapılmaktadır. Olumsuzlaştırma işlemi kelimenin köklerine me/ma, sı/siz gibi eklerin eklenmesiyle gerçekleştirilmektedir (Gezici \& Yanıkoğlu, 2018).

\subsection{Kelime Çantası (Bag of Words - BOW)}

Makine öğrenmesi yöntemiyle yapılan duygu analizi çalışmalarında, duygu sınıfı tespit edilecek metinlerin, bir şekilde bilgisayarın anlayabileceği şekle yani sayısal hale dönüştürülmesi gerekmektedir. Kelime çantası yöntemi, metinlerin sayısal hale dönüştürülmesine olanak sağlayan yöntemlerden biridir (Bag-ofWords model, 2007; Harris, 1954). Kelime çantası yönteminde sınıflandırma çalışması yapılan metnin tamamı terimlerine ayrılmaktadır. Oluşturulan her bir terim bir öznitelik olarak ele alınmaktadır. Daha sonra her bir özniteliğin yani terimin tüm metinde geçme sıklığı özniteliğin değeri olarak atanmaktadır. Böylece kategorik bir veri sayısal hale dönüştürülmektedir.

\subsection{Word2Vec}

Mikolov vd. (2013) tarafından alan yazına sunulmuş olan ve kelimeleri vektör olarak göstermeyi sağlayan yöntemlere Word2Vec denilmektedir. Word2Vec kelime temsil yönteminde yapay sinir ağları kullanılmaktadır ve denetimsiz öğrenme tekniğiyle kelimeler vektörlere dönüştürülmektedir. Word2 Vec yönteminde CBOW ve Skip-Gram adında iki model bulunmaktadır. Her iki modelde de pencere boyutu (window size) adı verilen bir giriş parametresi bulunmaktadır. Şekil 1'de görüleceği üzere CBOW (Continious Bag of Word) yani sürekli kelime torbas1 modelinde tahmin edilmek istenen kelimenin sağından ve solundan pencere boyutu parametresi kadar kelime yapay sinir ağına girdi olarak girmekte ve nihayetinde tahmin edilmek istenen kelimenin vektörü çıktı olarak elde edilmektedir. Skip-gram modelinde ise CBOW modelinin tam tersi bir işlem gerçekleştirilmektedir. Cümledeki bir kelime giriş olarak yapay sinir ağına girmekte, giriş yapılan kelimenin sağından ve solundan pencere boyutu parametresi kadarki kelimelerin vektörü çıktı olarak elde edilmektedir. Her iki modelde de işlemler tüm cümle tamamlanana kadar devam etmektedir (Aydoğan \& Karc1, 2019; Mikolov vd., 2013).

\subsection{FastText}

FastText, Facebook araştırma ekibi tarafından geliştirilmiş bir kelime temsil yöntemidir. Word2Vec yönteminin skip-gram alt yöntemine dayanmaktadır. Word2Vec yönteminde her bir kelime, en küçük birim olarak kullanılırken FastText yönteminde kelimeler n-gramlarına ayrılarak ele alınmaktadır. N-gramlarına ayrılan kelimeler, n-gramların toplamı olacak şekilde vektörel olarak temsil edilmektedir. N-gramları ele almayan diğer yöntemler, her bir kelimeyi bir vektöre dönüştürdükleri için

${ }^{2}$ Zemberek-NLP Türkçe için doğal dil işleme araçları sunan açık kaynak kodlu bir yazılımdır (Akın \& Akın, 2007). 


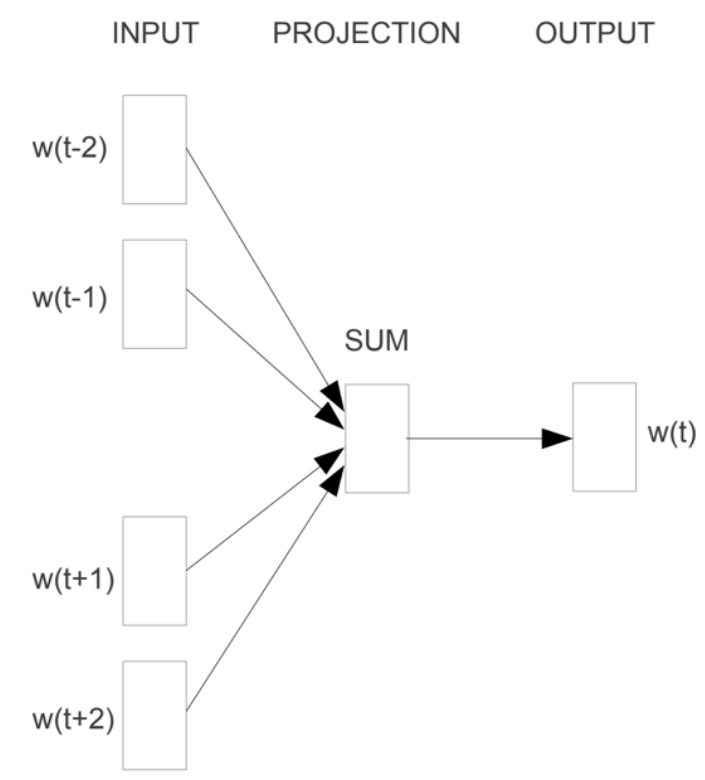

CBOW

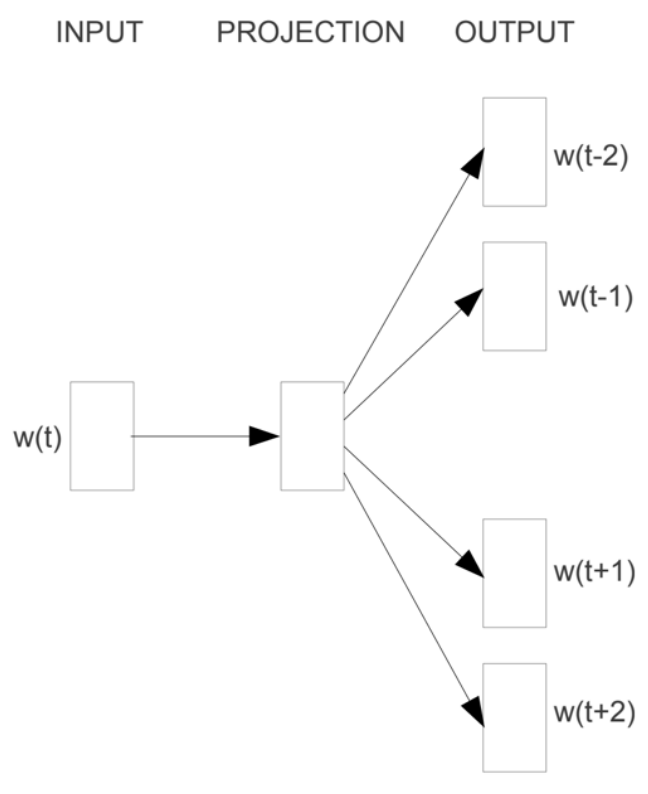

Skip-gram

Şekil 1. CBOW ve Skip-gram arasindaki fark. "Efficient Estimation of Word Representations in Vector Space” by Mikolov, T., Chen, K., Corrado, G. S., \& Dean, J., 2013, arXiv preprint arXiv:1301.3781. Copyright 2013 by arXiv.org.

kelimenin morfolojisini görmezden gelmektedirler. $\mathrm{Bu}$ durum özellikle büyük kelime dağarcığı olan ve çok nadir kelimelere sahip olan diller için bir sınırlandırma getirmektedir. FastText yöntemi n-gram yöntemi sayesinde bu sınırlamanın üstesinden gelmektedir (Bojanowski vd., 2017).

\section{Deneysel Kurulum}

$\mathrm{Bu}$ bölümde materyal ve metot kısmında bahsedilen karşılaştırmaları gerçekleştirebilmek için deneysel bir kurulum gerçekleştirilmiştir. Bu bölümün alt başlıklarında bu deneysel kurulumun gerçekleştirilme adımları sırasıyla verilmiştir.

\subsection{Verilerin Hazırlanması}

Materyal ve yöntem kısmında belirtildiği gibi çalışma için toplam 49031 adet inceleme çeşitli sosyal medya platformlarından toplanmıştır. Çalışma duygu analizi çalışması olduğu için verilerin analize hazır hale getirilmesi gerekmektedir. Verileri hazır hale getirebilmek için aşağıdaki işlemler gerçekleştirilmiştir.

1. Çalışmada sadece Türkçe dilinde yazılmış incelemeler kullanılacağı için, incelemelerin hangi dilde yazıldıklarının tespit edilmesi gerekmektedir. İncelemelerin dil değerleri Google tercüme servisindeki (Google Translation $\mathrm{API}^{3}$ ) dil algılama metodu kullanılarak tespit edilmiş ve Türkçe haricindeki incelemeler silinmiştir.

2. İncelemelerdeki harfler ve boşluk karakterleri haricindeki tüm diğer karakterler temizlenmiş ve tüm harfler küçük karaktere dönüştürülmüştür.

3. Kullanicilar sosyal medyada inceleme ya da yorum yazarken genellikle yazım kurallarına riayet etmemektedirler. $\mathrm{Bu}$ durum yazım hatalarına neden olmaktadır. Verilerdeki yazım hatalarını giderebilmek için veriler, Zemberek-NLP kullanılarak normalize edilmiştir.

4. Kelimeler öznitelik sayısını düşürmek amacıyla Zemberek-NLP kullanılarak köklerine ayrılmıştır.

5. Yöntem kısmında bahsedilen olumsuzlaştırma işlemi kelimelere uygulanmıştır.

6. Son olarak Sevindi (2013)'in çalışmasında kullandığı durak kelimeler veri setinden çıkarılmıştır.

Veriler üzerinde gerekli temizlik ve dönüştürme işlemleri yapıldıktan sonra geriye 527,232 kelimeden oluşan 37,912 adet inceleme kaydı kalmıştı ve veri setleri bu verilerle oluşturulmuştur.

\subsection{Karşılaştırma Esnasında Kullanılacak Veri Setlerinin Hazırlanması}

Çalışmada hem iki sınıflı duygu analizi hem de üç sınıflı duygu analizi gerçekleştirilmiştir. Bir önceki adımda duygu analizi için hazır hale getirilen veriler, incelemelere verilen puanlara göre etiketlenmiştir. Üçlü sınıflandırmada inceleme puanı bir ve iki olan veriler negatif, üç olanlar nötr, dört ve beş olanlar ise pozitif duygu polaritesine sahip olarak etiketlenmiştir. İkili sınıflandırma işleminde ise inceleme puanı bir ve iki olan veriler negatif, dört ve beş olan veriler ise pozitif olarak etiketlenmiştir. Etiketleme işlemi neticesinde Şekil 2'de görüldüğü gibi 3.458 kayıt negatif, 5556 kayıt nötr, 28898 kayıt ise pozitif olarak etiketlenerek sınıfları tayin edilmiştir.

Sağlıklı bir sınıflandırma işlemi yapabilmek için veri setlerinde her sınıftan eşit sayıda örnek olması gerekmektedir. Veri setlerinde her bir sınıftan eşit sayıda veri olmasını sağlamak

${ }^{3}$ Google Translation API, yüzü aşkın dili destekleyen bir tercüme ve dil algılama servisidir (Google, 2019). 
için her bir sınıftan örnek sayısı en az olan sınıfın örnek sayısı kadar örnek alınması gerekmektedir. Bu nedenle her bir sınıftan 3458 kayıt alınarak veri setleri oluşturulmuştur. Tablo 2'de görüldüğü gibi veri setleri sınıf sayılarına, veri setlerindeki kelimelerin köklerine ayrılma durumlarına ve olumsuzlaştırma durumlarına göre ayrılmaktadır. Testler VS1, VS2, VS3, VS4, VS5, VS6 olarak adlandırılan alt1 veri seti üzerinde gerçekleştirilmiştir.

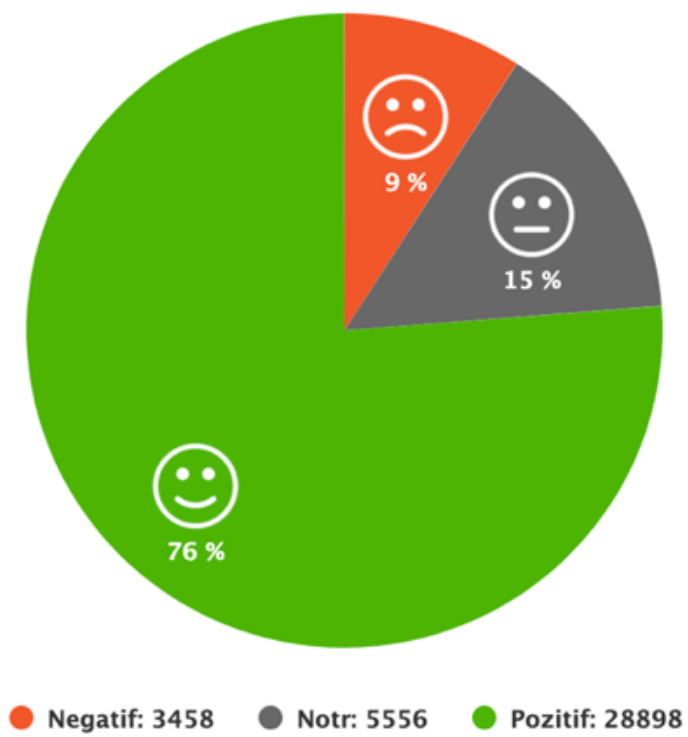

Şekil 2. Puana göre etiketleme neticesinde verilerin sinıflara dă̆llımı

\subsection{Deneylerin Gerçekleştirilmesi}

Bir önceki adımda açıklanan veri setleri kelime çantası kelime temsil yöntemiyle sayısal hale getirildikten sonra metin madenciliğinde sıklıkla kullanılan Naive Bayes (NB), Multinom Naive Bayes (MNB), k-Nearest Neighbor (k-NN) ve Support Vector Machines (SVM) algoritmaları WEKA programıla sınıflandırılmıştır (Witten vd., 2016). WEKA programında yapılan tüm sınıflandırmalar FilteredClassifier sınıflandırıcısıyla gerçekleştirilmiştir. WEKA programında gerçekleştirilen tüm ayarlamalar aşağıda maddeler halinde verilmiştir.

- Metinleri kelime çantası kelime temsil yöntemine göre sayısal hale dönüştürebilmek için FilteredClassifierin filter özelliği StringToWordVector olarak seçilmiştir.

- Literatürde sınıflandırma başarısına katkı sağladığ1 belirtildiğinden dolayı StringToWordVectorun TF Transformation ve IDF Transformation özellikleri True olarak işaretlenmiştir (Sevindi, 2013). Yani terimler TFIDF yöntemine göre ağırlıklandırılmıştır.

- k-Nearest Neighbor algoritmasında literatürdeki kullanımlar dikkate alınarak $\mathrm{k}$ değeri üç olarak ele alınmıştır (Silahtaroğlu, 2013). Diğer sınıflandırma algoritmalarında ise WEKA programının varsayılan parametreleri kullanılmıştır.

- Tüm veri setleri 10 tekrarlı çapraz doğrulama (10-fold cross-validation) yöntemiyle sinıflandırılarak kelime çantası yöntemine yönelik tüm test sonuçları elde edilmiştir.

Tüm veri setlerinin kelime çantası kelime temsil yöntemine göre test sonuçları elde edildikten sonra fastText kelime temsil yöntemine dair testler gerçekleştirilmiştir. FastText kelime temsil yöntemine yönelik testler python programlama dilinin fastText kütüphanesi kullanılarak gerçekleştirilmiştir (Joulin vd., 2017). FastText kelime temsil yöntemi için yapılan testler fastText kütüphanesinin otomatik parametre optimizasyonu kullanılarak yapılmıştır (Automatic hyperparameter optimization, n.d.). Böylece oluşturulan modeller için en uygun parametreler tespit edilebilmiştir. FastText kütüphanesinde tekrarlı çapraz doğrulama (cross-validation) özelliği olmadığı için bir python kodu ile tekrar sayısı 10 olacak şekilde çapraz doğrulama işlemi gerçekleştirilerek fastText kelime temsile yöntemine yönelik test sonuçları elde edilmiştir.

\subsection{Sınıflandırma Sonuçlarının Değerlendirilmesi}

Makine öğrenimiyle gerçekleştirilen sınıflandırma işlemlerinde sınıflandırma başarılarının değerlendirilmesi için genellikle doğruluk, duyarlılık, kesinlik ve f-ölçütü gibi metrikler kullanılmaktadır (Altunkaynak, 2017; Köse, 2018; Parlar \& Özel, 2016). Aşağıda bu metrikler kısaca açıklanmıştır.

\subsubsection{Doğruluk}

Sınıflandırılan kayıtların yüzde kaçının doğru bir şekilde sınıflandırıldığını gösteren bir metriktir. Doğru sınıflandırılmış kayıt sayısının toplam kayıt sayısına bölünmesiyle elde edilen bir değerdir. Doğruluk, iki sınıflı (pozitif, negatif) bir sınıflandırma işleminde Eşitlik 1'deki gibi hesaplanmaktadır (Köse, 2018).

$$
D o \text { grruluk }=\frac{T P+T N}{T P+T N+F P+F N}
$$

TP (True Pozitif) doğru bir şekilde pozitif olarak sınıflandırılmış kayıtların sayısını, TN (True Negatif) doğru bir şekilde negatif olarak sınıflandırılan kayıtların sayısını, FP (False Pozitif) negatif olması gerekirken pozitif olarak sınıflandırılmış

Tablo 2. Çalışmada kullanılan veri setleri

\begin{tabular}{c|l|c}
\hline Sinıflandırma Şekli & Köklerine Ayırma ve Olumsuzlaştırma Durumu & Veri Seti \\
\hline \multirow{2}{*}{ İkili } & Köklerine Ayrılmamış & VS1 \\
& Köklerine Ayrılmış ve Olumsuzlaştırma Yapılmamış & VS2 \\
& Köklerine Ayrılmış ve Olumsuzlaştırma Yapılmış & VS3 \\
\hline \multirow{2}{*}{ Üçlü } & Köklerine Ayrılmamış & VS4 \\
& Köklerine Ayrılmış ve Olumsuzlaştırma Yapılmamış & VS5 \\
& Köklerine Ayrılmışve Olumsuzlaştırma Yapılmış & VS6 \\
\hline
\end{tabular}


kayıtların sayısını, FN (False Negatif) pozitif olması gerekirken negatif olarak sınıflandırılmış kayıtların sayısı ifade etmektedir.

\subsubsection{Kesinlik}

Kesinlik, doğru sınıflandırılan kayıtların sayısının, toplam tahmin edilen pozitif sayısına bölünmesiyle Eşitlik 2'deki gibi hesaplanmaktadır. Kesinlik, sınıflandırma modelinin tahmin ettiği pozitiflerinin kaçının gerçek pozitif olduğunu belirten bir metriktir (Shung, 2020).

$$
\text { Kesinlik }=\frac{T P}{T P+F P}
$$

\subsubsection{Hassasiyet}

Doğru pozitif oranı (True Positive Rate - TPR) olarak da adlandırılmaktadır. Gerçek pozitiflerin ne kadarının doğru bir şekilde sınıflandırıldığını gösteren bir metriktir. Hassasiyet Eşitlik 3 'de gösterildiği gibi hesaplanmaktadır (Köse, 2018).

$$
\text { Hassasiyet }=\frac{T P}{T P+F N}
$$

\subsubsection{F Skoru}

Hassasiyet ve kesinlik metriklerinin harmonik otalamasından oluşan bir metriktir. Hem kesinliği hem hassasiyeti dikkate aldığ için birçok sınıflandırma işlemlerinde değerlendirme metriği olarak kullanılmaktadır (Altunkaynak, 2017; Chicco \& Jurman, 2020; F1 score, 2006). F-skoru Eşitlik 4'deki gibi hesaplanmaktadir.

$$
F \text { Skoru }=\frac{2 * \text { Kesinlik } * \text { Hassasiyet }}{\text { Kesinlik }+ \text { Hassasiyet }}
$$

\section{Araștırma Sonuçları ve Tartıșma}

Deneysel kurulum bölümünde bahsedilen testler gerçekleştirildikten sonra Tablo 3'deki sonuçlar elde edilmiştir. Tabloda kelime çantası ve fastText kelime temsil yöntemlerinin sınıflandırma sonuçları gösterilmektedir. Hem iki sınıflı hem de üç sınıflı duygu analizi işleminin sonuçları tabloda bulunmaktadır. Literatürdeki benzer çalışmalarda sınıflandırma başarılarının karşılaştırılmasında genellikle f-skorunun kullanıldığ1 görülmektedir (Alessa vd., 2018; Velioğlu vd., 2018). Çalışma sonucunda elde edilen sınıflandırma sonuçlarını literatürdeki diğer çalışmaların sonuçlarıyla karşılaştırabilmek için çalışmamızda sınıflandırma sonuçlarının değerlendirilmesinde f-skoru metriği kullanılmıştır ve Tablo 3'de çalışmada gerçekleştirilen sınıflandırma işlemlerinin f-skoru değerleri sunulmuştur.
Tablo 3 incelendiğinde iki sınıflı duygu analizi neticesinde kelime çantası kelime temsil yönteminin fastText kelime temsil yönteminden daha başarılı sınıflandırma işılemi gerçekleştirdiği görülmektedir. Üç sınıflı duygu analizi işlemindeyse tam tersi bir şekilde fastText kelime temsil yöntemi, kelime çantası kelime temsil yönteminden daha başarılı sınıflandırma işlemi gerçekleştirmiştir. İki sınıflı duygu analizi ve üç sınıflı duygu analizi sonuçlarına bakılınca iki kelime temsil yönteminin de sınıf sayısının artmasından olumsuz yönde etkilendiği görülmektedir.

Kelime çantası kelime temsil yöntemi kullanılarak yapılan sınıflandırma testleri neticesinde gerek iki sınıflı duygu analizi işleminde gerekse üç sınıflı duygu analizi işleminde en başarılı sınıflandırma işleminin SVM algoritması kullanılarak elde edildiği görülmektedir.

VS1 köklerine ayrılmamış iki sınıflı veri setini, VS2 köklerine ayrılmış ancak olumsuzlaştırma işlemi yapılmamış iki sınıflı veri setini, VS3 ise köklerine ayrılmış ve olumsuzlaştırma yapılmış iki sınıflı veri setini ifade etmektedir. Aynı şekilde VS4 köklerine ayrılmamış üç sınıflı veri setini, VS5 köklerine ayrılmış ancak olumsuzlaştırma işlemi yapılmamış üç sınıflı veri setini, VS6 ise köklerine ayrılmış ve olumsuzlaştırma yapılmış üç sınıflı veri setini ifade etmektedir. VS2 ve VS1 veri setlerinin sınıflandırma sonuçlarının farkı iki sınıflı duygu analizi işleminde köklerine ayırma işleminin sınıflandırma başarısına olan katkısını göstermektedir. Benzer şekilde VS3 ve VS2 veri setlerinin fark1 da iki sınıflı duygu analizi işleminde olumsuzlaştırma işleminin sınıflandırma başarısına olan katkısını göstermektedir. Üç sınıflı duygu analizi işleminde iki sınıflı duygu analizine benzer şekilde VS5 ve VS4 veri setlerinin sınıflandırma sonuçlarının farkı üç sınıflı duygu analizi işleminde köklerine ayırma işleminin sınıflandırma başarısına olan katkısını göstermektedir. VS6 ve VS5 veri setlerinin farkı da üç sınıflı duygu analizi işleminde olumsuzlaştırma işleminin sınıflandırma başarısına olan katkısını göstermektedir. $\mathrm{Bu}$ bilgiler 1şı̆̆ında Tablo 4 incelendiğinde köklerine ayırma ve olumsuzlaştırma işlemlerinin fastText kelime temsil yöntemiyle gerçekleştirilen duygu analizlerinde sınıflandırma başarısına olumlu ya da olumsuz bir etkisinin olmadığı görülmektedir. Kelime çantası kelime temsil yöntemiyle yapılan iki sınıflı duygu analizinde köklerine ayırma işlemi NB algoritmasında 0.02 'lik f-skoru katkısı getirirken MNB algoritmasında 0.01 'lik bir düşüşe sebebiyet vermiştir. Kelime çantası kelime temsil yöntemiyle yapılan üç sınıflı duygu analizinde ise köklerine ayırma işleminin MNB algoritması haricinde sınıflandırma başarısına katkı sağladığı görülmektedir. Benzer şekilde olumsuzlaştırma işleminin de SVM algoritması

\begin{tabular}{|c|c|c|c|c|c|c|}
\hline \multirow{2}{*}{$\begin{array}{c}\text { Sinıflandırma } \\
\text { Türü }\end{array}$} & \multirow{2}{*}{ Veri Setleri } & \multicolumn{4}{|c|}{ Kelime Çantası (TF-IDF) } & \multirow{2}{*}{$\begin{array}{l}\text { FastText } \\
\text { FastText }\end{array}$} \\
\hline & & NB & MNB & SVM & k-NN & \\
\hline \multirow{3}{*}{ İkili } & VS1 & 0.84 & 0.87 & 0.91 & 0.36 & 0.84 \\
\hline & VS2 & 0.86 & 0.86 & 0.91 & 0.36 & 0.84 \\
\hline & VS3 & 0.86 & 0.86 & 0.91 & 0.36 & 0.84 \\
\hline \multirow{3}{*}{ Üçlü } & VS4 & 0.59 & 0.63 & 0.70 & 0.20 & 0.78 \\
\hline & VS5 & 0.62 & 0.62 & 0.71 & 0.22 & 0.78 \\
\hline & VS6 & 0.63 & 0.63 & 0.71 & 0.23 & 0.78 \\
\hline
\end{tabular}
hariç sınıflandırma başarısına katkı sağladığı görülmektedir.

Tablo 3. Sınıflandırma Sonuçları 


\begin{tabular}{cc|cccc|c}
\hline \multirow{2}{*}{ Sinıflandırma Türü } & \multirow{3}{*}{ Veri Setleri } & \multicolumn{4}{|c|}{ Kelime Çantası (TF-IDF) } & FastText \\
\cline { 3 - 7 } & & NB & MNB & SVM & k-NN & FastText \\
\hline \multirow{2}{*}{ İkili } & VS2-VS1 & 0.02 & -0.01 & 0 & 0 & 0 \\
& VS3-VS2 & 0 & 0 & 0 & 0 & 0 \\
\hline \multirow{2}{*}{ Üçlü } & VS5-VS4 & 0.03 & -0.01 & 0.01 & 0.02 & 0 \\
& VS6-VS5 & 0.01 & 0,01 & 0 & 0.01 & 0 \\
\hline
\end{tabular}

\section{Sonuç}

Sosyal medya platformlarındaki verilerin hacmi düşünüldüğünde, sosyal medya platformlarında paylaşılan incelemeler ve deneyimler içerisinde kurumlar veya şirketler için anlamlı birtakım bilgilerin olduğu düşünülmektedir. Hal böyle olunca sosyal medyada paylaşlan incelemeler ve deneyimler içerisinden anlamlı bilgi çıkarma yöntemlerini daha iyi hale getirmek hangi yöntemin daha iyi olduğunu bilmek önem arz etmektedir. $\mathrm{Bu}$ nedenle bu çalışmada özellikle turizm yöneticilerini muhatap alan ve bir bölgedeki doğal ve kültürel varlıklar için duygu analizi yapmaya imkân sağlayan bir model geliştirmek hedeflenmiştir. Bu hedefi gerçekleştirirken de duygu analizinde kullanılan kelime temsil yöntemlerinden olan kelime çantası ve fastText kelime temsil yöntemi karşılaştırılarak, sınıflandırma başarısı yüksek olan yöntem tespit edilmeye çalışılmıştır. Ayrıca karşılaştırma işlemi gerçekleştirilirken kelimeleri köklerine ayırma ve kelimeleri olumsuzlaştırma işlemlerinin sınıflandırma başarısına katkılarının olup olmadığı ölçülmüştür. Yapılan karşılaştırma işlemleri neticesinde iki sınıflı duygu analizinde kelime çantası kelime temsil yönteminin fastText yönteminden daha başarılı sınıflandırma işlemi gerçekleştirdiği görülmüştür. Üç sınıflı duygu analizi işleminde ise tam tersi bir sonuç elde edilmiştir. Üç sınıflı duygu analizi işleminde fastText kelime temsil yöntemiyle gerçekleştirilen sınıflandırma işleminin daha başarılı olduğu tespit edilmiştir. Duygu analizi ön hazırlık işlemlerinden kelimeleri köklerine ayırma ve olumsuzlaştırma işlemlerinin fastText kelime temsil yöntemiyle gerçekleştirilen sınıflandırma işlemlerinde olumlu ya da olumsuz bir katkı sağlamadığı görülmüştür. FastText kelime temsil yöntemi kullanılarak elde edilen bu sonuç Kuyumcu v.d. (2019) çalışmasıyla paralellik göstermektedir. Bu durum fastText kelime temsil yöntemiyle gerçekleştirilen bir duygu analizi işleminde ön hazırlık işlemine gerek olmadığını göstermektedir. Kelime çantası kelime temsil yöntemi kullanılarak gerçekleştirilen duygu analizi işlemlerinde ise kelimeleri köklerine ayırma ve kelimeleri olumsuzlaştırma ön işlemlerinin sınıflandırma başarısına az da olsa bir katkısının olduğu tespit edilmiştir. Elde edilen bu sonucun da literatürdeki benzer çalışmalarla paralellik gösterdiği görülmektedir (Gezici \& Yanıkoğlu, 2018; Kaya vd., 2012). Sonraki çalışmalarda kelimeleri köklerine ayırma ve kelimeleri olumsuzlaştırma ön işlemlerinin geliştirilerek sınıflandırma başarısına olan katkılarının artırılması hedeflenmektedir.

İki sınıflı duygu analizinde en başarılı sınıflandırma sonucuna kelime çantası kelime temsil yöntemi kullanılarak $0.91 \mathrm{f}$-skoru değeriyle SVM algoritmasıyla oluşturulan makine öğrenmesi modeliyle ulaşılmıştır. Üç sınıflı duygu analizinde ise en başarılı sinıflandırma sonucuna 0.78 f-skoru değeriyle fastText kelime temsil yöntemi kullanılarak oluşturulan makine öğrenmesi modeliyle ulaşılmıştır. Literatürdeki Türkçe duygu analizi çalışmalarında klasik makine öğrenmesi algoritmaları kullanılarak gerçekleştirilen sınıflandırma sonucunda elde edilen f-skorlarının ikili sınıflandırmada 0.78 ile 0.921 arasında, üçlü sınıflandırmada ise 0.59 ile 0.78 arasında değiştiği görülmektedir (Çoban vd., 2015; Kaya vd., 2012; Kaynar vd., 2016; Velioğlu vd., 2018; Yıldırım vd., 2015). Bu çalışmada gerçekleştirilen duygu analizi işlemi neticesinde elde edilen sonuçlar benzer çalışmalarda elde dilen sonuçlarla paralellik göstermektedir. Bu durum bu çalışmada oluşturulan duygu analizi modelinin Türkçe turizm incelemeleri için kullanılabilir bir model olduğunu göstermektedir.

$\mathrm{Bu}$ çalşmada duygu analizindeki kelime temsil yöntemlerinden fastText ve kelime çantası kelime temsil yöntemleriyle oluşturulan sinıflandırma modellerinin sınıflandırma başarıları turistik mekanlar için yapılan Türkçe incelemeler kullanılarak karşılaştırılmış ve bir takım sonuçlar elde edilmiştir. Bu çalışmanın farklı alanlardaki Türkçe yorumlar ya da incelemelerle tekrar edilmesi, elde edilen sonuçların genellenebilirliği açısından önem arz etmektedir.

\section{Kaynakça}

Ait Hammou, B., Ait Lahcen, A., \& Mouline, S. (2020). Towards a real-time processing framework based on improved distributed recurrent neural network variants with fast Text for social big data analytics. Information Processing \& Management, $\quad 57(1), \quad 1-15$. https://doi.org/https://doi.org/10.1016/j.ipm.2019.102122

Akın, A. A., \& Akın, M. D. (2007). Zemberek, an open source NLP framework for Turkic Languages. Structure, 10, 1-5.

Albayrak, A. (2018). Duygu analizinde farkl vektör temsil yöntemleri ve sinıflayıcıların karşılaştırılması [Yüksek Lisans Tezi, Sivas Cumhuriyet Üniversitesi]. Sivas Cumhuriyet Üniversitesi Akademik Arşiv Sistemi. https://hdl.handle.net/20.500.12418/12071

Alessa, A., Faezipour, M., \& Alhassan, Z. (2018, June 4-7). Text classification of flu-related tweets using fasttext with sentiment and keyword features [Paper presentation]. 2018 IEEE International Conference on Healthcare Informatics, NY, USA.

Altunkaynak, B. (2017). Veri madenciliği yöntemleri ve $R$ uygulamaları. Seçkin Yayıncılık.

Automatic hyperparameter optimization. (n.d.). fastText. https://fasttext.cc/docs/en/autotune.html

Aydoğan, E., \& Akcayol, M. A. (2016, August 2-5). A comprehensive survey for sentiment analysis tasks using machine learning techniques [Paper presentation]. 2016 International Symposium on INnovations in Intelligent SysTems and Applications, Sinaia, Romania.

Aydoğan, M., \& Karc1, A. (2019). Kelime temsil yöntemleri ile kelime benzerliklerinin incelenmesi. Çukurova Üniversitesi Mühendislik-Mimarlkk Fakültesi Dergisi, 34(2), 181-196. 
https://doi.org/https://doi.org/10.21605/cukurovaummfd.609 $\underline{119}$

Baccianella, S., Esuli, A., \& Sebastiani, F. (2010, May 17-23). Sentiwordnet 3.0: an enhanced lexical resource for sentiment analysis and opinion mining [Paper presentation]. Proceedings of the Seventh International Conference on Language Resources and Evaluation, Valletta, Malta.

Bag-of-Words model. (2007, October 31). Retrieved July 20, 2020 from https://en.wikipedia.org/wiki/Bag-of-words model

Bilgin, M., \& Şentürk, İ. F. (2017, October 5-8). Sentiment analysis on Twitter data with semi-supervised Doc2Vec [Paper presentation]. 2017 International Conference on Computer Science and Engineering, Antalya, Turkey.

Bojanowski, P., Grave, E., Joulin, A., \& Mikolov, T. (2017). Enriching word vectors with subword information. Transactions of the Association for Computational Linguistics, $\quad 5, \quad 135-146$. https://doi.org/https://doi.org/10.1162/tacl a 00051

Can, Ü., \& Alataş, B. (2017). Duygu analizi ve fikir madenciliği algoritmalarının incelenmesi. International Journal of Pure and Applied Sciences, 3(1), 75-111. https://dergipark.org.tr/tr/pub/ijpas/issue/29969/304149

Chicco, D., \& Jurman, G. (2020). The advantages of the Matthews correlation coefficient (MCC) over F1 score and accuracy in binary classification evaluation. BMC genomics, 21(1), 6-6. https://doi.org/10.1186/s12864-019-6413-7

Çoban, Ö. (2016). Metin sınıflandırma teknikleri ile türkçe twitter duygu analizi [Yüksek Lisans Tezi, Atatürk Üniversitesi]. Atatürk Üniversitesi Dijital Arşiv Açık Erişim Sistemi. http://hdl.handle.net/123456789/4640

Çoban, Ö., Özyer, B., \& Özyer, G. T. (2015, May 16-19). Sentiment analysis for Turkish Twitter feeds [Paper presentation]. 2015 23nd Signal Processing and Communications Applications Conference, Malatya, Turkey.

Esuli, A., \& Sebastiani, F. (2006, May 22-28). Sentiwordnet: A publicly available lexical resource for opinion mining [Paper presentation]. Proceedings of the Fifth International Conference on Language Resources and Evaluation, Geona, Italy.

F1 score. (2006, February 9). Retrieved July 8, 2020 from https://en.wikipedia.org/wiki/F1_score

Gezici, G., \& Yanıkoğlu, B. (2018). Sentiment analysis in Turkish. In K. Oflazer \& M. Saraçlar (Eds.), Turkish Natural Language Processing (pp. 255-271). Springer International Publishing. https://doi.org/10.1007/978-3-319-90165-7 12

Google. (2019). Google Translation API. In [Application Program Interface]. https://cloud.google.com/translate/

Harris, Z. S. (1954). Distributional structure. Word, 10(2-3), 146162.

https://doi.org/https://doi.org/10.1080/00437956.1954.11659 $\underline{520}$

Joulin, A., Grave, E., Bojanowski, P., \& Mikolov, T. (2017, April 3-7). Bag of tricks for efficient text classification [Conference presentation]. Proceedings of the 15th Conference of the European Chapter of the Association for Computational Linguistics, Valencia, Spain.

Karaoğlan, K. M., Temizkan, V., \& Findık, O. (2019, April 2628). Sentiment analysis for hotel reviews with recurrent neural network architecture [Conference presentation]. International Conference on Advanced Technologies, Computer Engineering and Science, Alanya, Turkey.

Kaya, M., Fidan, G., \& Toroslu, I. H. (2012, December 4-7). Sentiment analysis of turkish political news [Paper presentation]. Proceedings of the The 2012 IEEE/WIC/ACM International Joint Conferences on Web Intelligence and Intelligent Agent Technology, Macau, China.

Kaynar, O., Görmez, Y., Y1ldı, M., \& Albayrak, A. (2016, September 17-18). Makine ögrenmesi yöntemleri ile duygu analizi [Paper presentation]. International Artificial Intelligence and Data Processing Symposium, Malatya, Turkey.

Kızılkaya, Y. M. (2018). Duygu analizi ve sosyal medya alanında uygulama [Doktora Tezi, Uludağ Üniversitesi]. Bursa Uludağ Üniversitesi Açı https://acikerisim.uludag.edu.tr/bitstream/11452/1058/1/516 866.pdf

Köse, İ. (2018). Veri madenciliği teori uygulama ve felsefesi. Papatya Yayıncılık Eğitim.

Ku, L.-W., Liang, Y.-T., \& Chen, H.-H. (2006, March 27-29). Opinion extraction, summarization and tracking in news and blog corpora [Paper presentation]. AAAI Spring Symposium, Stanford, CA, USA.

Kuyumcu, B., Aksakalli, C., \& Delil, S. (2019, June 28-30). An automated new approach in fast text classification (fastText): A case study for Turkish text classification without preprocessing [Paper presentation]. 3rd International Conference on Natural Language Processing and Information Retrieval, Tokushima, Japan.

Liu, B. (2012). Sentiment Analysis and Opinion Mining. Morgan \& Claypool Publishers.

Meral, M., \& Diri, B. (2014, April 23-25). Sentiment analysis on Twitter [Paper presentation]. 22nd Signal Processing and Communications Applications Conference, Trabzon, Turkey.

Mikolov, T., Chen, K., Corrado, G. S., \& Dean, J. (2013). Efficient Estimation of Word Representations in Vector Space. arXiv preprint arXiv: 1301.3781.

Neri, F., Aliprandi, C., Capeci, F., Cuadros, M., \& By, T. (2012, August 26-29). Sentiment analysis on social media [Paper presentation]. 2012 IEEE/ACM International Conference on Advances in Social Networks Analysis and Mining, İstanbul, Turkey.

Özyurt, B., \& Akçayol, M. A. (2018). Fikir madenciliği ve duygu analizi, yaklaşımlar, yöntemler üzerine bir araştırma. Selçuk Üniversitesi Mühendislik, Bilim Ve Teknoloji Dergisi, 6(4), 668-693.

http://sujest.selcuk.edu.tr/sumbtd/article/download/584/628

Pang, B., Lee, L., \& Vaithyanathan, S. (2002, July 6-7). Thumbs up? Sentiment classification using machine learning techniques [Paper presentation]. Proceedings of the Conference on Empirical Methods in Natural Language Processing Philadelphia, USA. https://doi.org/10.3115/1118693.1118704

Parlar, T., \& Özel, S. A. (2016, August 2-5). A new feature selection method for sentiment analysis of Turkish reviews [Paper presentation]. 2016 International Symposium on INnovations in Intelligent SysTems and Applications Sinaia, Romania.

Saad, M. K. (2010). The impact of text preprocessing and term weighting on arabic text classification [Master Thesis, The Islamic University ]. IUG Space. http://hdl.handle.net/20.500.12358/18770

Şeker, S. E. (2016). Duygu Analizi. Yönetim Bilişim Sistemleri Ansiklopedisi, 3(3), 21-36. http://ybsansiklopedi.com/wpcontent/uploads/2016/09/duygu_analizi.pdf

Sevindi, B. İ. (2013). Türkçe metinlerde denetimli ve sözlük tabanlı duygu analizi yaklaşımlarının karşılaştırılması 
[Yüksek Lisans Tezi, Gazi Üniversitesi, Yükseköğretim Kurulu Ulusal Tez Merkezi. https://tez.yok.gov.tr/UlusalTezMerkezi/tezDetay.jsp?id=hunBqU7X8Xef7VsYSve5g\&no=pshUKfJWw6uE0H0aVi WTEg

Shung, K. P. (2020, April 10). Accuracy, Precision, Recall or F1? Retrieved July 20, 2020 from https://towardsdatascience.com/accuracy-precision-recallor-f1-331fb37c5cb9

Silahtaroğlu, G. (2013). Veri madenciliği: Kavram ve algoritmaları. Papatya Yayıncılık Eğitim.

Türkmenoğlu, C. (2015). Türkçe metinlerde duygu analizi [Yüksek Lisans Tezi, İstanbul Teknik Üniversitesi]. İTÜ Dspace. http://hdl.handle.net/11527/12950

Türkmenoglu, C., \& Tantug, A. C. (2014, June 21-26). Sentiment analysis in Turkish media [Paper presentation]. Proceedings of the $31 \mathrm{st}$ International Conference on International Conference on Machine Learning, Beijing, China.
Velioğlu, R., Yıldız, T., \& Yıldırım, S. (2018, September 20-23). Sentiment analysis using learning approaches over emojis for Turkish tweets [Paper presentation]. 3rd International Conference on Computer Science and Application Engineering, Sanya, China.

Witten, I. H., Frank, E., Hall, M. A., \& Pal, C. J. (2016). The WEKA Workbench. Online Appendix for "Data Mining: Practical Machine Learning Tools and Techniques" (Fourth Edition ed.). Morgan Kaufmann.

Yıldırım, E., Çetin, F. S., Eryiğit, G., \& Temel, T. (2015). The impact of NLP on Turkish sentiment analysis. Türkiye Bilişim Vakf Bilgisayar Bilimleri ve Mühendisliği Dergisi, 7(1), 4151. https://dergipark.org.tr/tr/pub/tbbmd/issue/22247/238817

Yüksel, A. S., \& Gülşah, T. F. (2018). Metin madenciliği teknikleri ile sosyal ağlarda bilgi keşfi. Mühendislik Bilimleri ve Tasarim Dergisi, 6(2), 324-333. https://doi.org/https://doi.org/10.21923/jesd.384791 